\title{
Relaciones intertextuales entre "Alienación", cuento de Julio Ramón Ribeyro, y "Alienación", cortometraje de Alex Fischman*
}

Fecha de recepción: : 11 de agosto de 2021

Fecha de aprobación: 16 de octubre de 2021

\section{Resumen}

El cine y la literatura presentan estrechas relaciones, entre las cuales se destacan las adaptaciones. Para estudiar estas últimas se ha recurrido al criterio de dilucidar si el texto fílmico guarda fidelidad o no con el texto literario. Una manera de desarrollar este análisis es mediante la intertextualidad. Sin embargo, otros aportes teóricos complementan dicha perspectiva, tal como la transtextualidad de Genette o la transducción de Doležel. En este artículo se aplican estas categorías para abordar las relaciones que se establecen entre el cuento "Alienación" (1975) de Julio Ramón Ribeyro y el cortometraje "Alienación" (2019) de Alex Fischman. Nos interesa establecer si el texto de Fischman es solo una puesta en escena del relato de Ribeyro, o, en cambio, llega a resignificar el texto original al punto de convertirlo en uno diferente.

Palabras clave: Alex Fischman, Alienación, intertextualidad, Julio Ramón Ribeyro, transducción, transtextualidad.

Citar: Leonardo-Loayza, Richard. "Relaciones intertextuales entre "Alienación", cuento de Julio Ramón Ribeyro, y "Alienación”, cortometraje de Alex Fischman". La Palabra, num.40, 2021, e13274. (10) https://doi.org/ $\underline{10.19053 / 01218530 . \mathrm{n} 40.2021 .13274}$

\section{Richard Leonardo-Loayza}

Universidad Nacional Mayor de San Marcos. Doctor en Literatura Peruana y Latinoamericana y magíster en Literatura Peruana y Latinoamericana por la Universidad Nacional Mayor de San Marcos (UNMSM), magíster en Estudios Culturales por la Pontificia Universidad Católica del Perú. Es profesor en la Escuela de Literatura de la UNMSM y en la Escuela de Literatura de la UNFV. Investigador Renacyt (Grupo Carlos Monge - Nivel III), Código Renacyt: P0019388. Consejo Nacional de Ciencia y Tecnología e Innovación Tecnológica: Lima, PE. Código Scopus: 57217313124. Researcher id (WOS): aab-3494-2021.

(1) https://orcid.org/0000-00016867-2127

* Artículo de reflexión. 


\section{Intertextual relationships between "Alienación", a short story by Julio Ramón Ribeyro, and "Alienación”, a short film by Alex Fischman}

\section{Abstract:}

Cinema and literature have close relationships, among which adaptations stand out. To study the latter, the criterion of elucidating whether or not the filmic text is faithful to the literary text has been used. One way to develop this analysis is through intertextuality. However, other theoretical contributions complement this perspective, such as Genette's transtextuality or Doležel's transduction. In the article we apply these categories to address the relationships that are established between the short story "Alienación" (1975), by Julio Ramón Ribeyro and the short film "Alienación" (2019) by Alex Fischman. We are interested in establishing whether Fischman's text is just a staging of Ribeyro's story, or, instead, he comes to resignify the original text to the point of turning it into a different one.

Keywords: Alex Fischman, Alienation, Julio Ramón Ribeyro, intertextuality, transduction, transtextuality

\section{Relações intertextuais entre "Alienação", conto de Julio Ramón Ribeyro, e "Alienação", curta- metragem de Alex Fischman}

\section{Resumo}

O cinema e a literatura apresentam estreitas relações, dentre as quais salientam-se as adaptações. Para estudá-las, tem se utilizado o critério de dilucidar se o texto fílmico é fiel ou não ao texto literário. Uma forma de desenvolver a análise é a intertextualidade. No entanto, outros aportes teóricos complementam dita perspectiva, tais como a transtextualidade de Genette ou a transdução de Doležel. Neste artigo são usadas essas categorias para estudar as relações entre o conto "Alienação" (1975) de Julio Ramón Ribeyro e a curta-metragem "Alienação" (2019) de Alex Fischman. Interessa-nos estabelecer se o texto de Fischman é só uma encenação do relato de Ribeyro, ou, pelo contrário, ressignifica o texto original até o ponto de torná-lo em um diferente.

Palavras-chave: Alex Fischman, Alienação, intertextualidade, Julio Ramón Ribeyro, transdução, transtextualidade. 


\section{Introducción}

Nada lo reventaba más que no ser lo que uno no era.

-Julio Ramón Ribeyro “Alienación”

Desde el inicio del cine, la literatura fue considerada una de sus fuentes más importantes, debido a que se le reconocía la capacidad de "contar historias, lo que lo emparentaba con toda una tradición esencialmente literaria" (Peña-Ardid 54). De esta manera, se estableció un vínculo muy estrecho entre cine y literatura. Una de las manifestaciones más interesantes de dicha relación fue y sigue siendo la adaptación, en la que el realizador toma como referencia una obra literaria y crea una película. Se trata de un proceso por el cual el texto literario deviene en uno fílmico (Sánchez Noriega 47). De algún modo, este hecho ha provocado que se le exija al cine la fidelidad con el texto que adopta como modelo. Sin embargo, como prueba Robert Stam (61), tal fidelidad es un imposible, ya que se tratan de dos registros distintos, con recursos diferentes. No se toma en cuenta que la literatura y el cine se distinguen no solo en cuanto al canal que emplean para vehicular sus contenidos (la palabra y la imagen), sino que, también, son dos sistemas semióticos independientes.

A este respecto, Lauro Zavala considera que el filme que surge de un texto literario previo es una forma de traducción intrasemiótica. Esta traducción o "transemiotización", como la llaman Sánchez-Navarro y Lapaz Castillo (72), generalmente ha sido estudiada poniendo énfasis en la fidelidad del texto original, dejando de lado la especificidad del discurso cinematográfico. Como ha probado largamente Zavala, la aproximación a estas formas de intertextualidad, desde la perspectiva de la traducción intersemiótica, permite estudiar estas estrategias con mayor rigor, precisamente al ocuparse del estudio de las similitudes y diferencias de naturaleza formal, y no solamente de la dimensión temática e ideológica del proceso de adaptación (Zavala 46-47). Se busca así encontrar un equilibrio entre la forma y el contenido cuando se analiza la relación entre literatura y cine, lo que contribuiría a reconocer la autonomía de este segundo registro. Ahora bien, una manera de abordar esta traducción intersemiótica es la transducción (Doležel, Villanueva), esta no analiza la obra cinematográfica en términos de fidelidad o adulterio con respecto al texto literario (Potayo Sánchez 730), sino, cómo tiene lugar el camino forjado de las formas cinematográficas, a partir de las formas literarias de partida. De esa manera, la transducción se convierte en un instrumento pertinente para estudiar las relaciones entre una película y el libro que le sirve de base.

En 2019, en el Perú, se estrenó el cortometraje "Alienación” del cineasta Alex Fischman, el cual fue considerado "una adaptación libre" (Sánchez Noriega 65) del famoso cuento del mismo nombre, escrito por Julio Ramón Ribeyro, en 1975. En 2020, el filme fue parte de la selección oficial del Flickers Rhode Island Internacional Film Festival, semifinalista en el Festival Internacional de Cine de Buenos Aires y ganador del Premio "Diversity in the arts", en Los Angeles Diversity Film Festival. La crítica especializada peruana saludó con mucho agrado tales reconocimientos, resaltando la capacidad del director por haber conservado en su filme la esencia del texto base que sirvió para la adaptación. Como se aprecia, tal pers- 
pectiva valora la película por su fidelidad con el texto original, obviando las peculiaridades del filme. En este orden de ideas, resulta oportuno estudiar las relaciones que se establecen entre ambos textos, enfatizando en los aspectos que particularizan cada uno de ellos. Para desarrollar el siguiente análisis se emplea, principalmente, la teoría de la intertextualidad de Mijaíl Bajtin y Julia Kristeva, la transtextualidad de Gérard Genette y los aportes sobre la transducción de Lubomir Doležel.

\section{Intertextualidad, transtextualidad y transducción}

Para realizar el análisis de las relaciones textuales entre el cuento "Alienación" de Julio Ramón Ribeyro y el cortometraje del mismo título, de Alex Fischman, se debe apelar a una de las líneas de pensamiento más interesantes que, desde la perspectiva de la teoría literaria y cultural, se ha desarrollado a lo largo de la segunda mitad del siglo XX: la intertextualidad. Sobre los aportes de Mijaíl Bajtin acerca de la polifonía y el dialogismo, es Julia Kristeva quien acuña este término. Para la teórica búlgara, la palabra literaria no es un punto (un sentido fijo), sino un cruce de superficies textuales, un diálogo de varias escrituras del escritor, del destinatario (o del personaje), del contexto cultural anterior o actual. Así, todo texto literario "se construye como un mosaico de citas, todo texto es absorción y transformación de otro texto. En lugar de la noción de intersubjetividad se instala la de intertextualidad, y el lenguaje poético se lee, al menos, como doble" (Kristeva 190). De este modo, se entiende la intertextualidad como "la relación de un texto con otro u otros textos, la producción de un texto desde otros precedentes, la escritura como palimpsesto, en cuanto supone la preexistencia de otros textos, la lectura interactiva, lineal y tabular a la vez" (Martínez Fernández 37). A partir de este desarrollo, Gérard Genette, en 1982, publicó Palimpsestes, libro en el que redefine el objeto de la poética, que, en su opinión, no sería el texto, sino la transtextualidad o trascendencia textual del texto. De esta forma, señala cinco tipos de relaciones transtextuales: 1) la Intertextualidad, entendida como una relación de copresencia entre dos o más textos; la presencia efectiva de un texto en otro; su forma más explícita y literal es la cita; la menos explícita, el plagio; menos aún, la alusión; 2) la Paratextualidad, relación que se mantiene con su paratexto: título, subtítulo, intertítulo, prefacio, prólogo, epílogo, advertencia, notas al margen, al pie, al final; epígrafes, ilustraciones, sobrecubiertas, fajas, entre otros; 3) la Metatextualidad o relación del texto con otro que habla de él; incluye esencialmente la relación crítica; 4) la Hipertextualidad o relación que se une un texto B (hipotexto) a un texto anterior A (hipotexto), en el que se injerta de una manera que no es el comentario; hipotexto es todo texto derivado de otro anterior por transformación simple o transformación indirecta; y 5) la Architextualidad o conjunto de categorías generales o trascedentes de las que depende todo discurso (tipos de discurso, modos de enunciación, géneros literarios, por citar algunos) (Genette 10-14).

Ahora bien, un autor que ha enriquecido y ampliado el alcance teórico de la intertextualidad es Lubomír Doležel, quien considera que solo se ha apreciado un lado del fenómeno: la entrada del material textual existente en la formación de los textos sucesores. Para Doležel, el problema radica en que únicamente se ha estudiado lo que se hace con ese material, cómo se modela e integra en la totalidad del nuevo texto. En vista de esto, propone una categoría 
más abarcadora: la transducción, que explicaría el proceso de trasmisión y transformación de sentido en el que se prologan en el tiempo los textos literarios. Desde este paradigma, "el proceso de comunicación literaria no se agota en el 'circuito cerrado' de emisión-mensaje-recepción", pues "los textos literarios trascienden constantemente las barreras de los actos del lenguaje individuales y entran" al interior de unas "complejas cadenas de trasmisión o de procesamiento activo, que son condición necesaria para su supervivencia" y continuidad. Así, "el procesamiento lleva aparejadas transformaciones más o menos significativas de los textos" (Martínez 91). La transducción lleva consigo, por ende, "un doble mecanismo interconexionado: transmisión y transformación del sentido o, mejor, trasmisión con transformación, que tiene su origen en el 'circuito dividido' de la comunicación literaria, es decir, en la no copresencia o simultaneidad de emisor y receptor" (Martínez 90), con la consiguiente variación temporal, espacial y contextual entre el acto de la emisión y el acto de recepción, lo cual origina sucesivas interpretaciones (transformaciones) o reelaboraciones a lo largo de la cadena de trasmisión. La transducción permite al texto literario una vida activa a través de sucesivos e inacabables procesos de trasmisión con transformación del sentido. Doležel detalla:

La transducción literaria, en sentido lato, abarca fenómenos tan diversos como la tradición literaria, la intertextualidad, la influencia y la trasferencia intercultural. Las actividades de transducción incluyen la incorporación de un texto literario (o de alguna de sus partes) en otro texto, las transformaciones de un género en otro (novela en teatro, cine, libreto, etc.), traducción a lenguas extranjeras, crítica literaria, teoría e historia literarias, formación literaria y otras. En estos distintos "canales" de transducción se producen transformaciones textuales que abarcan desde citas literales hasta textos metateóricos substancialmente diferentes. (Historia breve 231-232)

Doležel estudia dos modos de trasmisión literaria: la recepción crítica y la adaptación literaria. Para el desarrollo de este artículo interesa ponerle atención al segundo modo. Por adaptación literaria entiende los modos de procesamiento activo en los que un texto literario se transforma en otro texto literario, entrando en tal proceso de adaptación de actividades como citar, aludir, imitar, reescribir en un género literario distinto, traducir, parodiar, plagiar y otras fuentes de intertextualidad literaria. Ahora bien, esta operación puede extrapolarse al cine, en ese sentido, podría hablarse de adaptación fílmica, pues, así como un texto literario puede transformarse en otro, de igual modo, el mismo texto puede transformarse, ser "traducido" (Zavala), transemiotizado (Sánchez-Navarro y Lapaz Castillo), en otro de naturaleza extraliteraria, como el de tipo audiovisual. Así, la transducción fílmica se entendería como "la actualización de una obra literaria por parte de un cineasta según un sesgo interpretativo acorde con su idiolecto y en sintonía con el horizonte de expectativas propio de los destinatarios potenciales, el público en el que piensa ese cineasta" (Potayo Sánchez 733).

\section{Relaciones textuales entre "Alienación" de Ribeyro y "Alienación" de Fischman}

Para entender mejor las relaciones que se establecen entre el relato de Julio Ramón Ribeyro y el cortometraje de Alex Fischman es necesario referir los argumentos de ambos textos. El cuento "Alienación" está incluido en el libro Silvio en el rosedal (1977) y forma parte del tercer tomo de La palabra del mudo, título que reúne toda la cuentística del autor peruano. El texto narra la historia de Roberto López, un muchacho afrodescendiente, pobre 
y que habita junto a su familia en el último callejón de un barrio limeño de clase media. En dicho barrio vive Queca, una joven hermosa, que no solo se convierte en el objeto de admiración de Roberto, sino en la de todos los muchachos del lugar. Un día, Roberto, sentado en una banca, mira cómo Queca juega con otros muchachos a la pelota. De pronto, el balón cae cerca de él y cuando intenta alcanzárselo a Queca, la muchacha se asusta y le dice que ella no juega con zambos. A partir de ese momento, la vida de Roberto cambió drásticamente. Se tiñó el cabello con agua oxigenada y se lo planchó, se blanqueó la cara con almidón, polvo de arroz y talco; luego se vistió siguiendo las modas estadounidenses (conseguía la ropa de segunda mano). Para completar su transformación, Roberto estudió inglés, primero de manera autodidacta y después en un instituto. Allí conoció a José María Cabanillas, otro afrodescendiente con aspiraciones similares a las suyas. Juntos se esforzaron como ningún otro estudiante, pero al ver que eran rechazados por la sociedad, que no encajaban en ningún lado y eran el centro de burlas, optaron por viajar a Estados Unidos. Para eso ahorraron durante un año; no obstante, el dinero que proyectaron para un semestre, apenas les duró un mes. Cuando creyeron que todo estaba perdido, se enteraron de que el Gobierno de Estados Unidos les prometía a los migrantes la nacionalidad, una pensión y otros beneficios si es que peleaban en la guerra contra Corea. Roberto, quien pasó a llamarse Bobby y luego Bob, no lo pensó mucho y junto con Cabanillas aceptaron. Meses más tarde, Bob murió en combate, mientras su compañero regresó al Perú sin un brazo. En el colofón del cuento, se narra que Queca se casó con un estadounidense, Billy Mulligan, quien se la llevó a su país. Al principio fueron felices, pero a medida que pasó un breve tiempo, el muchacho la empezó a golpear y llenarla de insultos tales como "chola de mierda".

Por otro lado, el cortometraje "Alienación" (2019) de Alex Fischman relata también la historia de Roberto López, pero ya no se trata de un afrodescendiente, sino de un cholo, es decir, un mestizo, producto de la fusión de las matrices etno-raciales blanca e indígena. Roberto habita en un barrio marginal y pobre, a las afueras de Lima, y un día mientras estaba jugando fulbito con unos amigos en una loseta deportiva, se percató de que había dos muchachas que estaban sentadas en las graderías. Una de ellas era Queca, la joven por la que se sentía atraído sentimentalmente. Al finalizar el juego, Roberto se dirigió hacia donde estaban las muchachas y mirando fijamente a Queca le dijo que si le gustaría salir con él. La muchacha le respondió que no salía con cholos. A partir de ese hecho, la vida de este muchacho se trasformó. Una tarde, sentado en un lugar desde donde se podía mirar la casa de su amada, Roberto vio que un muchacho rubio vino a recogerla, en un auto lujoso y con chofer. Antes de que se fueran, pudo escuchar que ambos jóvenes hablaban en inglés. Esa misma noche, Roberto compró un tinte barato y se pintó el cabello de rubio. Meses después ya no solo tenía el cabello teñido, sino que se había aclarado el rostro con una especie de crema y trabajaba en un parque de diversiones con un nombre en inglés. Aquí se encontró un día con José, un amigo del barrio que no veía hacía mucho tiempo. José le preguntó sobre los cambios que se había hecho Roberto, a lo que este último respondió, en primer lugar, con evasivas, pero luego confesó que era debido a que no quería ser un cholo. Ante tal respuesta, José le reclamó su actitud alienada y hubo un forcejeo, en el que Roberto llevó la peor parte. Algunas semanas después, fue a la casa de Queca, pero la madre de esta le contó que su hija se había casado con el gringo Mulligan y que ahora vivía en Estados Unidos. Entonces, Roberto intentó aplicar para una visa de turista que le permitiera entrar a ese país, pero fue rechazado. Así, decidió 
viajar como ilegal, pero cuando intentaba ingresar por la frontera cayó abatido por las balas de un desconocido en medio del desierto de Nacos, Arizona. La parte final del filme se centra en Queca, quien efectivamente vive en Estados Unidos con Nick Mulligan, pero en condiciones deplorables. La escena muestra que la muchacha le está cortando las uñas de los pies a su pareja. En eso, Queca se equivoca y hiere accidentalmente a Nick, el cual le propina un puntapié en la nariz diciéndole "chola de mierda".

Como puede notarse, el cortometraje de Fishman si bien conserva básicamente los contenidos del cuento de Ribeyro, modifica los pormenores de estos al punto de presentar un relato distinto. Puede decirse que se está ante un ejercicio de transtextualidad, en su modalidad de hipertextualidad, porque a partir de un determinado texto, se deriva otro. En este caso, el cuento de Ribeyro es el hipotexto, el texto base, y el cortometraje de Fischman es el hipertexto. Pero para hablar con propiedad y apelando a la teoría de Doležel, también se puede decir que este último texto es un producto de la transducción, ya que no se trata de otro texto escrito, como el cuento que le sirve de referencia, sino de un filme, un cortometraje, en el que se presentan una serie de cambios diegéticos y extradiegéticos. En esta traducción intrasemiótica o transemiotización, como explica Doležel: "El texto final es, al mismo tiempo, equivalente y diferente del texto original" (Heterocósmica 235). Se produce lo que Doležel denomina "equivalencia en la diferencia", es decir, "Todo acto de transducción afecta a ambos 'lados' del texto-signo; un texto primario in toto se transforma en un texto secundario in toto, es decir, en un nuevo texto con un significante y significado propios" (Heterocósmica 237).

De otra parte, en la traducción de un texto literario a uno cinematográfico se debe prestar atención tanto a los elementos de contenido como a los de forma, para establecer aquello que se conserva, se transforma o transduce, se elimina o se añade. Así, el primer cambio que se nota en el cortometraje respecto al cuento de Ribeyro es al nivel del título. Mientras que en el relato del escritor este paratexto es "Alienación (un cuento edificante seguido de un breve colofón)", el cortometraje de Alex Fischman solo lleva por título "Alienación”. El subtítulo entre paréntesis no deja de ser importante, porque desde el principio Ribeyro plantea con este último un protocolo de lectura que señala "el propósito admonitorio y el registro humorístico del texto" (Elmore, El perfil 215). Debe recordarse que el título o subtítulo de un texto es un "orientador de lectura" (Reis y Lopes). Así, los autores proponen la manera cómo deben leerse y entenderse sus textos. El título del relato de Ribeyro se corrobora con el desarrollo de las acciones del cuento, en el que se presenta, jocosamente, un intento fallido de movilidad social. Con justa razón, Julio Ortega ha llamado a esta narración: "sátira de la movilidad social" (139). En efecto, en el texto de Ribeyro, el que se narra en clave humorística, se puede advertir un cuestionamiento a los individuos que pretenden negar su origen y caen en la alienación en su tentativa de "ascender" socialmente. De esa manera, la interpretación que se ha hecho de "Alienación" lo inscribe como un texto que instruye sobre las consecuencias funestas de querer ser diferente a lo que se es, que pondera las consecuencias fatales de abandonar la identidad propia y tratar de asumir otra ajena (Ortega 139). La pretensión de Roberto es valorada como una situación que no debe seguirse como ejemplo, en la que su infortunio, como añade bien Elmore, "parece más bien una especie de justicia poética" (El perfil 216). 
Sin embargo, si se presta la atención debida, se apreciará que estos individuos pertenecen específicamente a los grupos subalternos que habitan la sociedad peruana, compuestos por afrodescendientes, indígenas y mestizos (los llamados "cholos"). Estos personajes son los cuestionados por querer asumir una identidad distinta a la de su origen. En esta línea de lectura, el destino final trágico del personaje principal del cuento de Ribeyro (que funciona como una metonimia de lo subalterno) obedece al deseo del grupo de poder blanco, de que los grupos menos favorecidos no pongan en riesgo el statu quo de la sociedad limeña, en la que la matriz blanca se asume como hegemónica y se arroga como superior al resto de matrices etno-raciales que conforman la nación peruana. De esta forma, el cuento "Alienación" se erige como una lección en negativo para aquellos que pretendan salir del lugar social que se les ha asignado y aspiran a integrar otra. Lo edificante es lo modélico, lo aleccionador, lo que sirve de ejemplo. Entonces, este es un relato que busca enseñar, ejemplificar aquello que no debe hacerse, es decir, renunciar a la propia identidad (étnica-racial o de clase) para anhelar otra, porque se puede terminar fatalmente como el personaje principal: Roberto.

El hecho de eliminar el subtítulo: "(un cuento edificante seguido de un breve colofón)" no es gratuito, sino que obedece a la intención de cambiar el registro en el que se contaba la historia. En el cortometraje de Fischman, si bien se narra una situación similar a la del cuento de Ribeyro, lo cierto es que no se pretende ejemplificar con la historia del personaje principal. Tampoco se da cabida al humor o la burla, y no se intenta resituar a los personajes según su etnia-raza o clase. Se trata más bien de evidenciar una tragedia, generada por la desigualdad social: el hecho de que un joven entienda que para alcanzar el amor de una muchacha debe cambiar de color de piel y estatus social, lo que lo lleva a la muerte. A diferencia del cuento de Ribeyro en el que se produce una especie de condena por desear ser otro, el cortometraje de Fischman lo que hace es detenerse en las razones que provocan dicha conducta. Aquí ya no se juzga, sino que se muestra las consecuencias de un fenómeno social como la alienación. En ese sentido, puede decirse que el filme de Fischman enmienda el error ideológico en el que cae el texto de Ribeyro, lo despoja de su sesgo de clase y de grupo étnico-racial. Fischman transduce el texto de Ribeyro, no solo lo traduce, al convertirlo en una película, sino que transforma su sentido.

Dentro de este orden de ideas, un aspecto en el que difieren ambos textos es en la representación que se elabora sobre los personajes que participan en los mismos. En el cuento resulta más que curioso cómo el narrador se refiere al protagonista, Roberto López, el cual es "un ser retaco, oscuro, bembudo y de pelo ensortijado" (Ribeyro, "Alienación" 103). O al jefe de Roberto en la pastelería, el cual es un personaje de origen andino: Cahuide Morales: "un mestizo huatón, ceñudo y regionalista, que adoraba los chicharrones y los valses crio1los" (Ribeyro, “Alienación” 107).1 Como se observa, el narrador se muestra poco amable a la hora de referirse a los personajes subalternos (afrodescendientes, indígenas y mestizos), hace ironía de ellos, incluso se burla, lo que no ocurre con los personajes de origen occi-

Cahuide corresponde al nombre de un capitán del imperio incaico que se inmoló en la fortaleza de Sacsayhuamán, en la Toma del Cusco, el 6 de mayo de 1536. El nombre no es gratuito en el texto de Ribeyro, más bien obedece a una intención de crear un efecto de humor en el relato. Por ejemplo, otro texto 
dental.2 Ahora bien, esta no es una característica privativa del cuento analizado, sino que se reitera en varios de los textos de Ribeyro, en los que la representación que se elabora sobre los personajes subalternos no está formulada en términos de una mera descripción, más bien son una especie de caricatura, en la que sobresale el uso del estereotipo, el exotismo y la ridiculización. ¿Puede afirmarse, entonces, que en la escritura de Ribeyro se presentan elementos racistas? Wolfang Luchting, uno de los críticos que más se ha dedicado al estudio de la obra de Ribeyro, señala que es posible que la representación sobre los afrodescendientes se deba a que este autor "los percibe como un elemento social inquietante, amenazante, como algo desconocido y potencialmente peligroso" (68). Lo cierto es que, sí se puede reconocer que hay una cierta predisposición en contra de dichos personajes. Esto no sucede en el cortometraje de Fischman. El relato no apela a estereotipos para definir a Roberto o los otros personajes que aparecen en la diégesis del cortometraje. No se está ante un intento de exotización u objetualización del subalterno. Lo que se aprecia, en cambio, es la puesta en escena de las formas es la que estos personajes enfrentan los escenarios de la desigualdad social, sin una pizca de humor o sorna.

Otro elemento que difiere del relato literario, y que se constituye en un añadido en el cortometraje, es un letrero que aparece en el inicio y en el que se presenta una definición:

\section{Cholo /sustantivo/}

(despectivo) Persona con ascendencia indígena.

Este paratexto es sumamente importante, porque no solo adelanta información sobre el personaje principal del filme, sino que, también permite entender cuál es la valoración social que trae consigo el ser identificado como parte integrante de este grupo etno-racial. En el cortometraje de Fischman el protagonista es un cholo, a diferencia del cuento de Ribeyro, en el que era un zambo (un negro). El motivo de esta decisión narrativa puede deberse a que en las últimas décadas la segregación etno-racial más notoria y agresiva en el Perú y, en especial, en Lima, se dirige en contra de los individuos que conforman la matriz indígena o mestiza, debido al gran número que habita la ciudad, como consecuencia de las migraciones producidas desde hace más cincuenta años. Lo anterior, no significa que haya desaparecido la discriminación hacia los afroperuanos, sino que esta ha sido invisibilizada (Kogan 16), opacada por aquella que se produce en contra de las personas de origen andino (indígenas y mestizos). Lo que hace Fischman, es actualizar el tema de la discriminación y el racismo en el Perú, pero poniendo el foco en el sujeto social que en el día de hoy se constituye en la víctima más perceptible de estos flagelos sociales. El texto de Fischman no pretende servir como un ejemplo de lo que no debe hacerse (movilizarse socialmente), sino que plasma la

\footnotetext{
2 Por ejemplo, otro texto en el que se nota esta peculiaridad de la narrativa ribeyriana es "Interior L". Aquí, el narrador se refiere a Allende, personaje afrodescendiente del cuento, en los siguientes términos: "Era el maestro de obras de una construcción vecina, un zambo fornido y bembón, hábil para decir un piropo, para patear una pelota y para darle un mal corte a quien se cruzara en su camino" (Ribeyro, "Interior L" 67). Y, más adelante, se dice acerca de este personaje que era: "un gigante con las manos manchadas de cal, el rostro salpicado de yeso y la enorme pasa zamba emergiendo bajo un gorro de papel" (Ribeyro, "Interior L" 68). Como se aprecia, no se está ante una descripción, sino una en la que se despliega un conjunto de estereotipos sobre lo afrodescendiente, que intentan convertirlo en objeto de escarnio.
} 
tragedia cotidiana que viven muchas personas que son definidas por el color de su piel o su condición social, lo que no les permite acceder a una serie de bienes simbólicos y materiales. En este aspecto, el texto de Ribeyro, que se manifiesta como conservador, es transducido en el filme de Fischman como un alegato que se alza en contra de la diferenciación social y la segregación.

Otra diferencia entre el cuento de Ribeyro y el cortometraje de Fischman es que, mientras el primero se preocupa básicamente por las acciones que se desarrollan en el relato, dejando de lado las descripciones de los espacios y de los objetos que ocupan estos últimos, el segundo pone énfasis en dichos elementos, pero no simplemente con una intención ornamental, la que sería utilizada para lograr la verosimilitud del relato, sino que cada espacio y objeto descritos pretenden darle sentido a la historia que se está narrando y a los personajes que participan de esta, es decir, ayudan en la significación del texto. En el cine "los espacios del relato producen sentidos denotados, pero sobre todo connotados" (Sánchez-Navarro y Lapaz Castillo 77) y que los objetos del decorado "sirven para otorgar un carácter reconocible a un espacio dado, de acuerdo con un tiempo, un lugar, un estado social y finalmente de acuerdo con gustos particulares (del director o de un personaje)" (Merlo 283). Para ilustrar este punto, debe recordarse que la imagen que abre estrictamente el filme es un plano panorámico en el que se muestra un barrio de escasos recursos económicos. La escena viene acompañada por el sonido de las olas del mar. En lo alto de un cerro, se levantan innumerables casas a medio construir, algunas hechas con material noble, otras, las más numerosas, apenas con materiales sencillos e informales. Se trata de un lugar en los márgenes de la ciudad, el cual es habitado, en su mayor parte, por los migrantes andinos (los cholos). La presentación de este espacio está asociada con la identidad de los personajes que lo ocupan, que es una identidad en construcción, pero en la que resalta la heterogeneidad, la pobreza y la informalidad. Lo mismo ocurre en la escena en la que Roberto está jugando fútbol con sus amigos en una loseta deportiva, antes de recibir el desaire de Queca. Mientras se escucha una melodía de tipo andino, la cámara realiza un travelling alrededor de la loseta lo que muestra es: calles sin pavimentar, basura, perros miccionando en la acera. No hay duda de que se quiere enfatizar en el carácter pobre de los personajes y el lugar que habitan. Se instaura un "marco de sentido" (Abril 106) específico: la carencia. Dicho marco se reafirma cuando del plano panorámico inicial, la cámara pasa a enfocar una de las viviendas, quizá una de las más rústicas de todas. Las paredes son de madera o triplay, el techo de calamina (sobre la que hay una diversidad de cosas viejas y botadas). La cámara ingresa a una de las habitaciones de la vivienda. En la escena interior, se puede ver a Roberto vestido apenas con calzoncillos, sentado al filo de la cama. Pareciera que está viendo la televisión, pero no le hace caso, entre sus manos tiene un libro. El enfoque de la cámara está dispuesto de tal manera que no solo se aprecia al muchacho, sino su habitación en conjunto. Podría decirse que es más importante mostrar la habitación que al personaje mismo. El espacio que se contempla es modesto, desarreglado y atiborrado de objetos disímiles que se han ido acumulando con el tiempo. De esa manera, se está diciendo que Roberto no solo es pobre, sino que su existencia está marcada por el desorden, por el abandono. Como se advierte, los espacios y los objetos distribuidos en ellos permiten entender no solo el entorno del protagonista, sino que, suministra datos sobre su personalidad, pero, a la vez, también expresa mucho acerca del grupo étnico-racial al que pertenece dicho personaje. 
Otro de los elementos que se transducen en el cortometraje de Fischman respecto al cuento de Ribeyro es la historia del relato (como se vio líneas atrás, en la presentación de los argumentos). Ribeyro cuenta básicamente los pormenores de un deseo de cambio a partir del desprecio que experimenta Roberto por parte de Queca, la muchacha más hermosa del barrio, y que él, en secreto, admiraba. El narrador relata:

Fue una fatídica bola que alguien arrojó esa tarde y que Queca no llegó a alcanzar y que rodó hacia la banca donde Roberto, solitario, observaba. ¡Era la ocasión que esperaba desde hacía tanto tiempo! De un salto aterrizó en el césped, gateó entre los macizos de flores, saltó el seto de granadilla, metió los pies en una acequia y atrapó la pelota que estaba a punto de terminar en las ruedas de un auto. Pero cuando se la alcanzaba, Queca, que estiraba ya las manos pareció cambiar de lente, observar algo que nunca había mirado [...], algo que tampoco le era desconocido, que había tal vez visto como veía todos los días las bancas o los ficus, y entonces se apartó aterrorizada.

Roberto no olvidó nunca la frase que pronunció Queca al alejarse a la carrera: "Yo no juego con zambos". Esas cinco palabras decidieron su vida. (Ribeyro, "Alienación” 103)

Este suceso marcó la vida de Roberto, porque le sirvió para entender el modo en el que funcionan algunos de los mecanismos del mundo social peruano, en el cual un "zambo" (un afrodescendiente) no tiene valor, es un cuerpo abyecto, que produce rechazo y temor. En el decurso del relato las vidas de Roberto y Queca jamás volverán a encontrarse. En cambio, en el filme de Fischman este desencuentro no solo es fundante en la historia de vida del protagonista, sino que mucho de lo que haga este último está relacionado con el anhelo de alcanzar el amor de Queca. En el cortometraje, Roberto está jugando fulbito en la loseta con sus amigos y Queca, junto con una amiga, son las únicas personas que ocupan las graderías. Al final del partido, y en uno de los extremos de la loseta deportiva, José, el muchacho que fue a buscar a Roberto para jugar la pichanga, trae una botella de cerveza y se la alcanza junto con un vaso. Roberto se sirve y le dice a José:

$$
\begin{aligned}
& \text { Roberto: "Lo voy a hacer”. } \\
& \text { José: “¿Qué? ¿Queca? No te creo". } \\
& \text { Roberto: "Mírame”. }
\end{aligned}
$$

El protagonista camina hacia las dos muchachas y dirigiéndose a la más blanca de las dos le dice: "Queca, sé que no hablamos mucho, pero te quería preguntar si quisieras salir conmigo". Queca le sonríe a su compañera y, luego de un instante, le responde a Roberto, de forma cortante: "No salgo con cholos". El muchacho queda impávido, solo atina a marcharse, sin decir nada. A diferencia del cuento de Ribeyro en el que solo se presenta la escena del desprecio, en el cortometraje de Fischman hay una explicación al por qué Roberto se atreve a invitar a Queca a salir. Para esto, resulta necesario volver a la primera escena del filme y poner atención en el libro que está agarrando el protagonista. Se trata de Juan Salvador Gaviota (1970), de Richard Bach. Este texto se constituyó en uno de los más famosos libros de 
autoayuda o superación de los últimos cincuenta años. Relata la historia de un personaje antropomorfizado que no aceptaba seguir la rutina, sino que entendía que la vida es un constante reto, en el que el pensamiento y la voluntad lo son todo. Aquí se produce un fenómeno de intertextualidad entre lo que enseña el libro de Bach y aquello que sucede con el protagonista del cortometraje. Roberto ha interiorizado la lección que trasmite el libro y busca aplicarlo en su propia vida. Se debe recordar, junto a Tilsa Ponce Romero, que la idea central de todos estos libros de autoayuda "es la del poder ilimitado de la mente. A partir de un control de los pensamientos, sería posible ganar amigos, volverse rico y llegar a ser una persona de éxito" (36). Roberto está convencido de que es suficiente el poder de la mente y la voluntad para lograr lo que se proponga, en este caso invitar a salir a Queca, pero no lo consigue. A partir de ese momento, se percata de que el deseo no es el único factor que determina que se alcance aquello que se quiere, sino que hay otros elementos preponderantes y que son de carácter externo, como lo social o lo étnico-racial. El hecho de que el cortometraje brinde una explicación sobre los motivos que llevaron a Roberto a intentar abordar a Queca, prueba de que este texto de Fishman no solo trasmite la historia del cuento de Ribeyro, sino que la transforma, ampliándola y permitiendo, así, que se pueda entender mejor a su protagonista.

Debe resaltarse que tanto el cuento de Ribeyro como el filme de Fischman coinciden en que los protagonistas de ambos textos realizan un aprendizaje sobre la vida social, a partir del rechazo del objeto amado. Los dos personajes entienden que dicha situación se debe a que poseen una serie de rasgos físicos que son considerados negativos en el imaginario de la sociedad, los que les impiden acceder a determinados bienes que ofrece esta última. Lo que hacen ambos protagonistas es identificar estos rasgos, que están básicamente relacionados con la raza-etnia. Así, se percatan de que en el Perú existe la desigualdad étnico-racial, que ser zambo o cholo es un estigma, lo cual se constituye en un poderoso obstáculo en la consecución de lo que se desea en la vida social. Por esta razón, lo que procuran ambos personajes es cambiar su apariencia, blanquearse, porque han descubierto que lo blanco está en lo más alto de la escala social, pero no cualquier blanco, sino uno de tipo extranjero, un "gringo". Por ejemplo, en el cuento de Ribeyro, el narrador expresa:

La vida se encargó de enseñarle que si quería triunfar en una ciudad colonial más valía saltar las etapas intermediarias y ser antes que un blanquito de acá un gringo de allá. Toda su tarea en los años que lo conocí consistió en deslopizarse y desambarse lo más pronto posible y en americanizarse antes de que le cayera el huaico y lo convirtiera para siempre, digamos, en un portero de banco o en chofer de colectivo (“Alienación” 101)

Roberto entiende que, la sociedad peruana es racista, que el color de su piel es considerado un disvalor, entonces lo que pretende es desarrollar una estrategia para superar esta eventualidad. El narrador explica:

Había un estado superior, habitado por seres que planeaban sin macularse sobre la ciudad gris y a quienes se cedía sin peleas los mejores frutos de la tierra. El problema estaba en cómo llegar a ser un Mulligan [un gringo] siendo un zambo. Pero el sufrimiento aguza también el ingenio, cuando no mata, y Roberto se había librado a un largo escrutinio y trazado un plan de acción. (“Alienación” 105) 
Como se indica, Roberto actúa en función de un plan, que ha trazado a lo largo de los años y que consiste en eliminar aquellos rasgos de su persona que no son aceptados socialmente. En cambio, en el cortometraje de Fischman, Roberto merodea la casa de Queca y un día ve que ha venido a recogerla, en un carro lujoso y con chofer, un joven rubio. Roberto sabe que se trata de un extranjero, porque se comunica en inglés con Queca. La pareja ingresa al auto, recorren el cerro de subida. Este último detalle no es gratuito, pues el director está adelantando la significación que tendrá este muchacho en la vida de Queca, el cual se constituirá en el medio que le permitirá la movilización social, el ascenso anhelado. Pero a la par, este hecho también es importante para Roberto, ya que gracias a esto entenderá que solo convirtiéndose en un gringo podrá conseguir el amor de la amada. La prueba de lo que se afirma es que Roberto esa noche regresó a su casa y se pintó el cabello. A diferencia del personaje de Ribeyro en el que se produce un aprendizaje dilatado, en el filme de Fischman, la certeza de lo que se debe hacer para obtener lo deseado es espontáneo y rápido.

Una cuestión importante es que, a partir de lo mostrado anteriormente, se puede sostener que ambos personajes han desarrollado la capacidad de agencia, es decir, que estos individuos toman conciencia de las circunstancias que le son adversas y deciden hacer algo para superarlas. Los dos personajes encarnan la figura del agente que, como explica Amartya Sen, es la "persona que actúa y provoca cambios" (36). Este término está asociado a la praxis, la que es la puesta en acto de la capacidad de "actuar" (Arendt 201). El hecho de querer dejar de ser negro o cholo para convertirse en un blanco es una acción que pretende mejorar sus condiciones de vida, no importa lo cuestionable que pueda ser dicho empeño. A este respecto, no se debe olvidar que la agencia no tiene nada que ver con el hecho de que aquello que se realice sea considerado bueno o malo; los logros pueden y deben juzgarse en función de los "valores y objetivos, independientemente de que los evaluemos o no también en función de algunos criterios externos" (Sen 36). Claude Bremond, en su ensayo "La lógica de los posibles narrativos", afirma que todos los personajes que intervienen en un relato son los protagonistas de las historias que viven, cada personaje "es su propio héroe" (92). Esta consideración podría extrapolarse a las éticas que desarrollan los diferentes personajes que participan en la diégesis de un relato. Todos actúan en función de un propósito, sea correcto o incorrecto, se logre o no.

Un añadido interesante es que, mientras en el cuento el lector es el que llegará a evaluar la conducta de Roberto López como una manifestación de la alienación, corroborando así lo que el autor propone mediante el título del texto, en el cortometraje es uno de los personajes el que aludirá a este término, calificando de este modo la conducta del protagonista. Luego de que Roberto se pinta el cabello por primera vez, en el relato fílmico han pasado dos meses. La cámara muestra al protagonista trabajando en un parque de diversiones. Lleva uniforme, el cabello rubio y se ha aclarado el rostro. Mientras está barriendo, ha reconocido entre el público que visita el parque a José, el amigo de su barrio que se vio en el inicio del filme:

José: "Hola, hermano. ¿Qué es de tu vida, huevón? Peluca me contó que el otro día te vio cuando salía con Stephanie. Me contó que estabas todo blanco y que te habías pintado el pelo".

Roberto: “Un pequeño arreglo nomás. Quería parecerme a los artistas de Hollywood”. 
José: “¿Qué? ¿Por qué? ¿Te da roche [vergüenza] ser peruano?”

Roberto: "Me contaron que estás estudiando en la San Marcos. ¿Qué tal está?"

José: “No me cambies el tema, huevón. ¿Te da vergüenza ser peruano?”

Roberto: "No quería ser un cholo".

José: “¿Por eso te pintaste la cara? Mira a tu alrededor, huevón. ¿Tú qué crees que es esto? ¿Disney? Te puedes maquillar todo lo que quieras, pero por dentro vas a seguir siendo del barrio [...] Alienado de mierda".

José acaba de interpelar al protagonista, le ha recriminado el hecho de querer ser otro, de renunciar a su identidad. Resulta interesante la razón que Roberto le da para justificar ese cambio: quería parecerse a los artistas de Hollywood. Pero ante la incredulidad de José, Roberto termina aceptando que lo hizo porque no quería ser un cholo, es decir, no quería ser discriminado, humillado, ofendido. José no entiende tal situación, lo reduce a una simple cuestión de nacionalismo, por eso, le recuerda que por más artilugio que se haga, igual seguirá siendo un cholo. Se debe resaltar que José habla desde la posición del saber, es un estudiante de una universidad prestigiosa y, por lo tanto, ha experimentado un proceso de segunda socialización, por el que puede llevar a cabo el ejercicio crítico de una situación social (la que cataloga como un acto de alienación). Roberto, por el contrario, no tiene acceso a esa ventaja, hace lo que cree es lo correcto, aunque esto implique intentar ser otro.

Lo anterior está asociado con una peculiaridad que posee el cortometraje de Fischman y que no tiene el cuento de Ribeyro: el abordaje de la interioridad (lo que, como se vio párrafos atrás, estará relacionado a la descripción de los espacios y los objetos que pueblan los mismos). Por ejemplo, luego del incidente con José se presenta nuevamente en un plano panorámico el barrio donde vive Roberto, pero es de noche y apenas hay unas cuantas luminarias alumbrando el lugar, las cuales parpadean. Un racord permite que se vea una de las calles aledañas a la casa del protagonista. Todo está solitario y sombrío, apenas se escuchan unos ladridos de perros. El siguiente plano muestra a Roberto en su habitación, se está mirando ante el espejo del baño. Con una especie de rabia contenida, mira su cabello rubio. Mientras llora, se lo jala violentamente. De improviso, le propina un golpe a su imagen en el espejo, trisándolo. Unas gotas de sangre caen en el lavabo. El muchacho sigue llorando, pero al ver su sangre levanta la cabeza y muestra un gesto desafiante frente a lo que queda del espejo. Como se pueda apreciar, la descripción del espacio en el que se desarrollan los acontecimientos está vinculado al estado de ánimo en el que se encuentra Roberto, luego del desencuentro con José. Este estado se grafica bien en la escena interior, gracias a la cual se sabe que Roberto sufre, pero a pesar de todo está dispuesto a seguir con sus planes. Así, el cortometraje, a diferencia del cuento, trabaja más extensamente la subjetividad del protagonista, explora en su intimidad. Mientras en el texto de Ribeyro, el personaje Roberto es esquemático, monolítico (jamás se hace referencias a sus emociones), el de Fischman se muestra con matices, lo que no solo lo hace verosímil, sino humano. 
En el cuento de Ribeyro, las vidas de Roberto y Queca nunca más se cruzaron; en cambio, en el cortometraje, Queca siempre está presente en la vida y el pensamiento de Roberto. Por eso, cuando este cree que ya logró transformarse totalmente en un gringo, va a buscar a la muchacha. Una mujer mayor le atiende y él le dice que es Bobby, un excompañero del colegio de Queca. La mujer le informa que su hija ya no vive allí, que se casó con el gringo Nick Mulligan (en el cuento de Ribeyro se llamaba Billy) y que, ahora, se radicó en Estados Unidos. Roberto se despide, ofuscado. La siguiente escena lo presenta en una cabina pública de Internet. Sentado frente a una computadora, acaba de abrir su correo electrónico. La cámara muestra parte del texto que la embajada norteamericana le ha enviado, negándole la visa de turista (por el correo recién el espectador se entera que el muchacho se llama Roberto López). En el cuento de Ribeyro, Roberto puede viajar libremente como turista a Estados Unidos, no hay ningún tipo de restricción, en cambio, el personaje de Fischman enfrenta otros tiempos, más difíciles, menos amables con los migrantes. Roberto, al verse impedido de viajar, decide viajar como un ilegal.

La escena final en la que aparece Roberto se inicia con un plano panorámico, en el cual se aprecia un desierto. Un paratexto escrito indica que está en la localidad de Naco, Arizona, en la frontera de México y Estados Unidos. La cámara desciende y encuadra a Roberto, quien está tendido en el suelo, sangrando del lado derecho del vientre. A lo lejos hay un hombre que le está disparando con una escopeta. Roberto intenta huir, pero el hombre, de apariencia estadounidense, vuelve a disparar y esta vez mata al muchacho. Se produce un plano medio. Roberto yace sin vida, con los ojos abiertos y con una mancha de sangre que va rodeando su cabeza. En el cuento de Ribeyro, Roberto muere en la guerra contra Corea defendiendo a Estados Unidos. El lector no asiste al deceso del protagonista. Tan solo se tiene el testimonio de su amigo Cabanillas y los informes que envían los militares norteamericanos a la madre de Roberto, quien fallece de la impresión. Resulta interesante notar que el cuerpo de Roberto, el del cuento de Ribeyro, es traído al Perú, mientras que el del protagonista del filme de Fischman queda varado en medio del desierto, el cual será olvidado como tantos otros cuerpos de los latinoamericanos que intentan ingresar a los Estados Unidos clandestinamente, con el afán de lograr el sueño americano. En ese sentido, el cuerpo del cholo ya no solo es un cuerpo abyecto, sino uno que no importa; es desechable, olvidable.

La última comparación que se realizará es respecto al personaje de Queca. Un aspecto que la crítica ha soslayado es que, en el cuento de Ribeyro, no solo hay un protagonista, sino que esta condición, Roberto la comparte con Queca. A pesar de que, se menciona esporádicamente los pormenores del trayecto de vida de esta muchacha, lo cierto es que también le servirá al narrador para ejemplificar lo que no se debe hacer. El narrador relata que este personaje, desde niña, ya poseía un plan para mejorar su vida. Así, seleccionaba a sus amistades, descartando a los más "trigueños" (Ribeyro, “Alienación” 103). Se fijó en Chalo Sander, el muchacho que "tenía el pelo más claro, el cutis sonrosado y que estudiaba en un colegio de curas norteamericanos" (“Alienación” 103). Pero luego lo cambió por Billy Mulligan, hijo de un funcionario del consulado de Estados Unidos. Esto lleva a que el narrador diga:

Del grupo al tipo y del tipo al individuo, Queca había al fin empuñado su carta. Solo Mulligan la llevaría al altar, con todas las de la ley, como sucedió después y tendría derecho a acariciar 
esos muslos con los que tanto, durante años, tan inútilmente soñamos. (Ribeyro, "Alienación" 105)

Como puede advertirse, Queca es representada como una mujer arribista y calculadora, que es consciente que tiene en su cuerpo la fórmula ideal para lograr el ascenso social. Cuestión que se le acepta, a diferencia de Roberto, al cual no se le perdona su extracción social ni el color de su piel, aspectos que de alguna manera comparten con la muchacha. Así lo confirma el narrador al decir:

Queca no estudiaba con las monjas alemanas del Santa Úrsula, ni con las norteamericanas del Villa María, sino con las españolas de la Reparación, pero eso nos tenía sin cuidado, así que como su padre fuera un empleadito que iba a trabajar en ómnibus o que su casa tuviera un solo piso y geranios en lugar de rosas. Lo que contaba entonces era su tez capulí, sus ojos verdes, su melena castaña, su manera de correr, de reír, de saltar y sus invencibles piernas, siempre descubiertas y doradas y que con el tiempo serían legendarias. (Ribeyro, "Alienación” 102)

No resulta determinante el hecho de que Queca sea pobre ni que pertenezca al sector mestizo de la población (“tez capulí"). Esas eventualidades poco o nada importan, porque ella es hermosa y dueña de un cuerpo excepcional. En la diégesis del relato literario, la muchacha pareciera entender que una persona con sus características físicas puede lograr la movilización social. En una sociedad patriarcal y androcéntrica, como la peruana, en la que la mujer ha sido históricamente cosificada, reificada y valorada por su cuerpo (la mención recurrente que se formula en el relato a las piernas de Queca es más que significativa),3 lo que hace esta muchacha es utilizar precisamente dicho cuerpo como un instrumento a su favor. En esta línea de sentido, también el proceder de Queca debe ser visto como la acción protagonizada por un agente, el que, luego de identificar las ventajas y desventajas de su situación, llega a operar un cambio. Si bien al final no tiene éxito (opera sobre ella la justicia poética, el disfraz del deseo de la élite de no permitir la movilidad social), lo importante es que ha intentado superar sus circunstancias y ser feliz.

En el cortometraje de Fischman, el personaje de Queca es soslayado. Si bien desempeña un papel importante en el desarrollo de los acontecimientos referidos a Roberto, lo cierto es que casi no aparece en el cortometraje. Solo cuando está junto con su amiga viendo el partido de fulbito que juega Roberto, escena en la que rechaza la invitación de este para salir. Luego, cuando Roberto presencia que Nick Mulligan viene a recogerla en un auto. Y, finalmente, en la escena del epílogo, en la que, según informa un paratexto, está en Nueva York y recibe el puntapié de Mulligan, por haberlo herido accidentalmente. Pese a esta fugacidad en sus apariciones, se puede decir que este personaje también tiene agencia, porque reconoce el lugar que se le ha asignado en la sociedad y decide hacer algo para cambiarlo y mejorarlo, no importa que su intento haya terminado en fracaso.

Las piernas de Queca, "símbolo de erotismo y sensualidad en el relato" (Churampi), son consideradas un arma de seducción poderosa por parte del narrador. Estas piernas son catalogadas de diferente modo a lo largo del relato, primero como "invencibles" ("Alienación" 102), luego, "triunfales" ("Alienación" 103), y, finalmente, como un trofeo para aquel que se case con ella, lo cual le daba derecho "de acariciar esos muslos" ("Alienación" 105) con los que tanto soñaban, tanto el narrador como los muchachos de su barrio. 


\section{Conclusiones}

Respecto a la trama, el cortometraje de Fischman mantiene de manera parcial los hechos que se narran en el cuento de Ribeyro, pero lo que hace el texto de Fischman es transducirlo, adecuarlo a la época contemporánea. Para eso, cambia la extracción étnica-racial del protagonista, el cual ya no es un afrodescendiente, sino un cholo, es decir, la mezcla de un blanco con un indígena. Asimismo, la historia ya no se desarrolla en el centro de la ciudad, sino en uno de sus márgenes, lo que implica también dejar constancia de los cambios urbanos que ha experimentado Lima en las últimas décadas, en las que los subalternos han sido arrojados más allá de los extramuros de la ciudad.

Una cuestión que se enfatiza en la diégesis del cortometraje es que Roberto López está apasionado por Queca, lo que no sucede en el cuento, en el que luego del desplante que le hace la muchacha, el protagonista no busca entrar en contacto con ella. En cambio, el personaje de Fischman siempre está pendiente de la muchacha, la vigila por un tiempo y cuando cree que ya se produjo la transformación, la va a buscar a su casa. Aunque en el texto fílmico no se diga, lo cierto es que una de las razones principales para que Roberto quiera viajar a Estados Unidos lo constituye la búsqueda de Queca. A diferencia del Roberto López del cuento de Ribeyro, el de Fischman no logra entrar a Estados Unidos de una manera legal, tampoco enfrenta una guerra y mucho menos muere como consecuencia de esta, sino que debe ingresar clandestinamente y cae abatido por un miembro de una organización racista, que aparentemente se dedica a la caza de migrantes.

El cambio más importante que presenta el cortometraje es la postura ideológica del director respecto a los personajes, las historias que viven y el sentido del texto. El tono de la obra de Fischman no reproduce lo jocoso y burlesco del cuento de Ribeyro. A este realizador no le interesa ridiculizar a sus personajes, sino que los presenta como seres humanos que anhelan determinados bienes simbólicos y materiales que ofrece la sociedad, pero los cuales están impedidos de alcanzar por su identidad etno-racial o su procedencia de clase. Es difícil reírse del destino de Roberto, el cual, como tantos otros latinoamericanos, luchan a diario en contra de la discriminación y el racismo en sus países. Lo mismo sucede con Queca, quien termina sufriendo violencia de género. En este sentido, más que ser una historia edificante, aleccionadora (como pretende ser el cuento de Ribeyro), se está ante un relato que evidencia el intento por superar unas circunstancias que se consideran adversas para alcanzar los objetivos propuestos. No se advierte un juicio respecto a las conductas de los personajes, solo se las presenta, exhibiendo algunas de las circunstancias que las generan.

El texto de Fischman es una traducción intersemiótica, una transemiotización, una transducción del texto de Ribeyro, pero como tal no se queda simplemente en tratar de encajar los contenidos de este último texto en un filme. El cortometraje de Fischman se encarga no solo de adaptar el relato, sino que lo convierte en un artefacto político, que pretende mostrar las estructuras de desigualdad y su vigencia a lo largo del tiempo. De esta manera, Fischman está señalando que, pese a que han pasado tantas décadas desde la aparición del relato de Ribeyro, lo que se cuenta allí aún está sucediendo en el Perú de hoy, en el cual negros, indígenas y 
mestizos siguen siendo víctimas del racismo y la segregación etno-racial. El texto de Fischman reescribe el cuento de Ribeyro, lo adecua según su idiolecto. Por eso, se puede decir que este cortometraje no solo es una puesta en escena del relato de Ribeyro, sino que llega a resignificarlo, al punto de convertirlo en uno diferente.

\section{Referencias}

Abril, Gonzalo. Cultura visual, de la semiótica a la política. Madrid: Plaza y Valdés Editores, 2013.

Arendt, Hannah. La condición humana. Buenos Aires: Paidós, 1998.

Bach, Richard. Juan Salvador Gaviota. Barcelona: Ediciones B, 2014.

Bremond, Claude. "La lógica de los posibles narrativos". Análisis estructural del relato. Buenos Aires: Editorial Tiempo Contemporáneo, 1970, pp. 87-109.

Churampi, Adriana. "El espejismo de los modelos de identidad. Lectura de Alienación de Julio Ramón Ribeyro." Espéculo. Revista de Estudios Literarios, núm. 44 (2010). Web. 18 jul. 2021. https://dialnet.unirioja.es/servlet/articulo? codigo $=3177806$

Doležel, Lubomír. Historia breve de la poética. Madrid: Síntesis, 1997.

----. Heterocósmica. Ficción y mundos posibles. Madrid: Arco/Libros, 1999

Elmore, Peter. El perfil de la palabra. La obra de Julio Ramón Ribeyro. Lima: Fondo Editorial de la Pontificia Universidad Católica del Perú y Fondo de Cultura Económica, 2002.

Fischman Cárdenas, Alex. Alienación, 2019. https://vimeo.com/452392162. Fecha de consulta: 18 agost. 2021.

Genette, Gérard. Palimpsestos. La literatura en segundo grado. Madrid: Taurus, 1989.

Kogan. Liuba. Profesionales afroperua@s en Lima: un drama anunciado. Lima: Universidad del Pacífico, 2014. 
Kristeva, Julia. Semiótica 1. Madrid: Editorial Fundamentos, 1981.

Luchting, Wolfgang A. "Zambas y zambos en la obra de Julio Ramón Ribeyro”. Socialismo y Participación, núm. 31, sept. (1985): 65-73. Web. 15 jul. 2021. http://www.geocities.ws/munaqaa/Wolfgang.pdf

Martínez Fernández, José Enrique. La intertextualidad literaria. Base teórica y práctica textual. Madrid: Cátedra, 2001.

Merlo, Alessandra. Los útiles y los inútiles. Presencia y visibilidad de los objetos en el cine. Bogotá: Universidad de los Andes, 2017.

Ortega, Julio. "Los cuentos de Ribeyro". Cuadernos Hispanoamericanos, núm. 417, mar. (1985): 128-145. Web. Web. 10 jul. 2021. http://www.cervantesvirtual. com/obra/los-cuentos-de-ribeyro/

Peña-Ardid, Carmen. Literatura y cine. Madrid: Cátedra, 1992.

Ponce Romero, Tilsa. "Los libros de 'autoayuda' y la construcción de una narrativa del sujeto contemporáneo". Industriales culturales. Máquina de deseos en el mundo contemporáneo. Ed. Santiago López Maguiña, Gonzalo Portocarrero, Rocío Silva Santisteban, Juan Carlos Ubilluz y Víctor Vich. Lima: Red para el Desarrollo de las Ciencias Sociales, 2007, pp. 35-49. https://repositorio.up.edu.pe/bitstream/handle/11354/988/LopezSantiago2007.pdf?sequence $=1 \&$ isAllowed $=\mathrm{y}$

Potayo Sánchez, Pedro. "La transducción al cine de la novela Tristana: la forma cinematográfica buñueliana”. Revista Signa, núm. 23 (2014): 731-752. Web. 10 jul. 2021. https://dialnet.unirioja.es/descarga/articulo/4526829.pdf

Reis, Carlos, Ana Cristina Lopes. Diccionario de narratología. Salamanca: Ediciones Almar, 2002.

Ribeyro, Julio Ramón. “Interior L”. La palabra del mudo. Tomo I. Lima: Seix Barral, 2009, pp. 65-73.

----. "Alienación (cuento edificante seguido de breve colofón)". La palabra del mudo. Tomo III. Lima: Seix Barral, 2009, pp. 101-113.

Sen, Amartya. Desarrollo y libertad. Buenos Aires: Planeta, 2000. 
Sánchez-Navarro, Jordi y Lola Lapaz Castillo. ¿Cómo analizar un videoclip desde el punto de vista narrativo? Barcelona: Editorial UOC, 2015.

Sánchez Noriega, José Luis. De la literatura al cine. Barcelona: Paidós, 2000.

Stam, Robert. "Beyond Fidelity: The dialogics of adaptation". Film Adaptation. Ed. James Naremore. New Jersey: Rutgers University Press, 2000, pp. 54-76.

Villanueva, Darío. “Autobiografía (Camilo José Cela) y biografía (Ricardo Franco) de Pascual Duarte". El realismo y sus formas en el cine rural español. Ed. Pedro Poyato. Córdoba: Diputación de Córdoba, Ayuntamiento de Dos Torres, 2009, pp. 51-84.

Zavala, Lauro. "La traducción intersemiótica en el cine de ficción". CIENCIA ergo-sum, Revista Científica Multidisciplinaria de Prospectiva. vol. 16, núm. 1, marzo-junio (2009): 47-54. Web. 18 jul. 2021. https://www.redalyc.org/pdf/104/10416106.pdf

Richard Leonardo-Loayza (Arequipa, Perú). Doctor en Literatura Peruana y Latinoamericana por la Universidad Nacional Mayor de San Marcos (UNMSM). Magíster en Literatura Peruana y Latinoamericana por la misma casa de estudios. Magíster en Estudios Culturales por la Pontificia Universidad Católica del Perú (PUCP). Es autor de los libros La letra, la imagen y el cuerpo. Ensayos sobre literatura, cine y performance (Hipocampo editores, 2012), El cuerpo mirado. La narrativa afroperuana del siglo xx (Universidad San Ignacio de Loyola, 2016, 2017). Editor de los libros Poéticas de lo negro. Literatura y otros discursos sobre lo afroperuano en el siglo xx (Hipocampo editores, 2013) y Bajo la piel. Asedios a la literatura afrolatinoamericana (Polisemia editores, 2019). Se desempeña como profesor en la Escuela de Literatura de la UNMSM y en la Escuela de Literatura de la UNFV. Investigador Renacyt (Grupo Carlos Monge - Nivel III), Código Renacyt: P0019388. Consejo Nacional de Ciencia y Tecnología e Innovación Tecnológica: Lima, PE. Código Scopus: 57217313124. Researcher id (WOS): aab-3494-2021. 